\title{
The Effect of Changing Grading Criteria on Student Writing
}

\author{
Darlene E. Crone-Todd, Heidi L. Eyre, Scott A. Hutchens, J. Reid Jones, and Joseph J. Pear
}

\begin{abstract}
Students enrolled in a senior-level psychology course used a computer-aided personalized system of instruction (CAPSI) to write tests, and give and receive feedback on their writing at a mastery level. Weekly measures of the number of unit tests requested, the number of unit tests cancelled, and informal student feedback all indicate that a change in the feedback to allow revision of answers increased student persistence and activity in CAPSI.

Keywords: Writing, Computer-aided PSI (CAPSI), student persistence and activity
\end{abstract}

In Spring 2004, Delta State University surveyed freshmen and seniors using the National Survey of Student Engagement (NSSE, 2000; see Bridges \& Kuh, 2004). The results of the NSSE report indicated many significant strengths of Delta State, including high levels of student-student and studentfaculty interaction and many positive aspects of writing (e.g., preparing several drafts, and receiving prompt feedback). However, the NSSE results did indicate that students at Delta State engage in less writing than students at comparable institutions. As suggested by Tierney and Shanahan (1991), there is a strong link between writing and thinking. Thus, one area that Delta State has targeted is to increase is the amount of writing that students produce during their four-year undergraduate degrees.

The current study began as a way to increase student reading and writing skills within an upperlevel psychology course at Delta State University. This course incorporates stress on the written word through use of a computer-aided personalized system of instruction (CAPSI, see Pear \& Crone-Todd, 1999). With its basis in Keller's (1968) personalized system of instruction (PSI), CAPSI incorporates many of the features of the original system (Grant \& Spencer, 2003), including: (a) the written word as the main means of learning the material; (b) mastery criteria for passing unit tests prior to continuing on in the testing; (c) self-paced method for students to progress at their own speed; (d) use of proctors, tutors, or peer reviewers to provide feedback and help administer the program; (e) lectures as motivational aids, rather than as the main means of transmitting information.

The growth of PSI-taught courses coincided with research indicating its clear effectiveness as a pedagogical tool that increased performance well over the previous gains using lecture or discussionbased learning (Buskist, Cush, \& DeGrandpre, 1991; Johnson \& Ruskin, 1977; Kulik, Kulik, \& Cohen, 1979). This work showed that PSI students learned more than students taught using conventional methods. When compared with other methods, PSI courses were perceived by students as more demanding, yet were also rated as more favorable in quality and enjoyment.

Despite this early advantage for PSI, the system fell out of favor for a variety of reasons. One of the key reasons was due to the amount of time for instructors to set up and administer these courses (Buskist et al, 1991). However, recent advances in technology have resurrected an interest in the PSI methodology. In particular, CAPSI (Pear \& Crone-Todd, 1999; Pear \& Kinsner, 1988) has been used for the last few decades at the University of Manitoba to teach several undergraduate courses in psychology, and is now being made available through the internet to serve locations throughout Canada and the United States.

CAPSI incorporates the principles of PSI by focusing on small units of study. The students are provided with open-ended study questions that correspond to each unit. Students are allowed to proceed at their own pace to master the units on tests based on these study questions. These unit tests are reviewed by the instructor or two peer-reviewers to determine if mastery is met. Feedback on each question is provided, and if the answers to all questions meet mastery criteria, the test is evaluated as a pass. If any of 
the questions do not meet mastery criteria, then the test is evaluated as a restudy. However, there is no penalty for a restudy: The same unit is simply retested as described above until mastery criteria are met before the student may move on to the next unit. During the last few years, research on CAPSI has centered on the development of critical, or higher-order, thinking skills (HOT; see Crone-Todd \& Pear, 2001; Crone-Todd, Pear, \& Read, 2000; Pear, Crone-Todd, Wirth, \& Simister, 2001); the quality of, and compliance with, feedback on unit tests (Martin, Pear, \& Martin, 2002a;b); and the theoretical underpinnings of CAPSI in terms of constructivistic and behavioristic approach to pedagogical philosophy and application (Pear \& Crone-Todd, 2002).

A key part of the learning in CAPSI takes place through the use of feedback between students and more-able peers. But what is feedback? Peterson (1982) suggests that feedback can take on many different usages that are not well-defined. In CAPSI, feedback on the outcome of a unit test has often been in the form of a restudy or pass. In any case, we likely expect that through the processes involved in feedback that our students should develop some sort of rules (Martin \& Pear, 2003) or heuristics, with which they can solve problems or answer questions in the future. Through the judicious use of shaping and fading procedures from the verbal community for following these rules appropriately, students learn to emit mastery-level performance. The processes involved in shaping and fading in the process of learning is what social constructivists term "scaffolding" in "constructing knowledge" (Pear \& CroneTodd, 2002). The restudy was meant to provide feedback that should indicate to the student what needed to be revised to attain mastery on that unit. While the restudy has typically been seen by both educators and researchers as a non-punitive outcome for answers that did not meet criteria simply because the student could try again (e.g., Keller, 1968), if the feedback were to result in students requesting and submitting less unit tests, then from a behavioral perspective, the restudies would necessarily be defined as punitive in nature.

During the term in which the first author taught a CAPSI-assisted senior-level psychology course, low levels of student persistence indicated that the restudies may be serving a punitive function. Thus, changes in the feedback provided to students for unit test mastery were incorporated. The purpose of this research, then, is to determine the pedagogical effectiveness of these changes.

\author{
Method
}

\title{
Participants
}

The participants were 14 undergraduate psychology students (12 females and 2 males; $29 \%$ African-American, and 71\% Caucasian) enrolled in a senior-level Applied Behavior Analysis course at Delta State University. All fourteen of these student gave signed informed consent, and these students are included in the study.

\section{Materials and Equipment}

A dedicated website was designed by the first author to serve as a place for students to download all course materials, including a general course manual which provided syllabus content and detailed information about how to use CAPSI, and the unit study questions.

CAPSI (http://www.webcapsi.com) ran on a University of Manitoba server, and was used to administer and record all aspects of the PSI-related course activities, including unit tests, peer reviewing, and email. Computers were available on the Delta State campus in labs and in the library for students' access, or they could login from any location that has an internet connection.

Design and Procedure 
The design used in this research is an interrupted time series design (Goodwin, 2005), in which measures of student behavior are taken both before and after an event that occurred in the middle of the series (i.e., change in mastery criteria in the middle of the term). The independent variable is the conditional result, which was either not available, or available. The dependent variables include the number of students who requested tests, number of cancelled tests, number of tests passed, number of restudies, and the percentage of students who attempted unit tests, per week in the course.

As part of the course procedures, students were instructed in how to use CAPSI to take unit tests within a 60 minute time period. Upon request, CAPSI would randomly select three questions from a given unit and present them to the student. The student then typed and saved their answer in a text box under each question. When complete, the student could cancel (if they did not feel adequately prepared) or submit the test for review.

A submitted test is sent for anonymous review to either two peer reviewers (students who had previously mastered the given unit) or to the instructor. If the test was sent to two peer reviewers, both had to independently agree that the test was a "pass". Otherwise, it was a restudy. The instructor could render a "pass" or "restudy" individually. "Mastery criteria" was defined as having complete and correct answers to all questions. Each unit must be passed before the student may move on to the next unit. Students may appeal any restudy decision through CAPSI by providing a good argument for why their answer was correct. The appeal would then be sent to the instructor, who can render a decision.

There were 15 unit tests, with the first unit test based on the course manual and the rest based on the course textbook (Martin \& Pear, 2003). Students were encouraged to work through the unit tests on a weekly basis. By the eleventh week of class, a decline in unit test writing was observed, so the "conditional pass" was incorporated another alternative. An instruction was given to all students that if a test was near mastery, then a "conditional" pass would be given, and that the student could use the appeal function to provide a revised answer to the instructor.

After final grades were calculated and submitted at the end of the term, the data were analyzed using the following method. The total number of unit tests attempted during the four full course weeks preceding, and following, email and an in-class announcement indicating that a conditional pass would be available. In addition, the number of unit tests cancelled for each student, by week, were recorded. As a measure of consumer satisfaction, qualitative results are reported based on classroom observations and communication with students in the course.

\section{Results}

\section{Quantitative Results}

Figure 1 displays the total number of requested tests by week in course. Note that for 11 of the students, that there was a statistically significant increase $(t=3.03, p=<.005,1$-tailed $)$ in the number of tests requested after the conditional was introduced $(M=6.00, S D=4.51)$ when compared to the four weeks prior to the announcement $(\mathrm{M}=2.57, \mathrm{SD}=2.31)$. Figure 2 shows the number of cancelled tests reduced in number after the conditional was introduced $(\mathrm{M}=0.93, \mathrm{SD}=1.27)$ when compared with the four weeks prior to the announcement $(\mathrm{M}=1.86, \mathrm{SD}=2.18)$. Note that 11 of the students either reduced, or kept constant, the number of cancelled tests. It is also important to realize that this was not just a select group of students increasing their writing activity: a greater proportion of students attempted tests after the conditional pass was added. Taken together, the decrease in cancelled tests and the increase in requested unit tests provides evidence that the restudy results may have been serving as punishers, rather than as feedback to encourage changes in test answers. In addition, the conditional decision appears to have served as a less punitive way to encourage revised writing. 


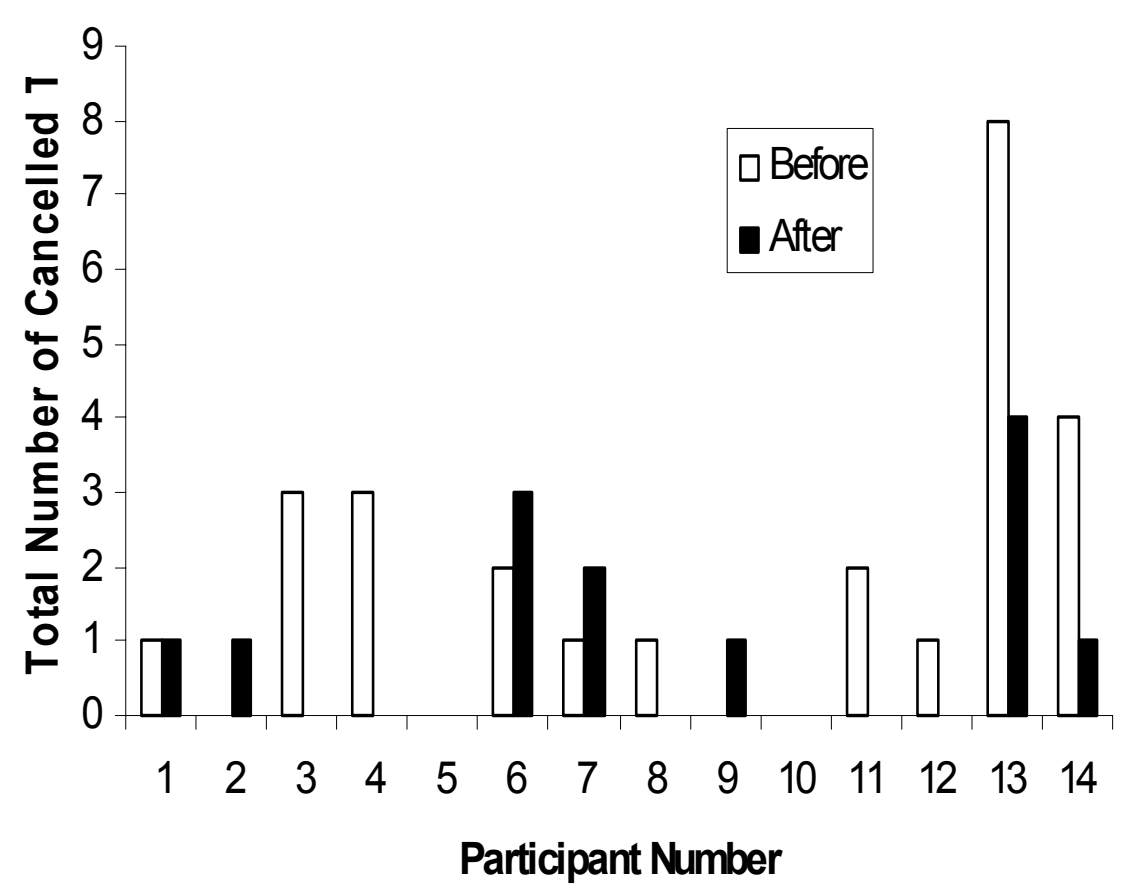

Figure 1. The total number of requested tests, by student, during the four full weeks before and after the conditional pass was introduced.

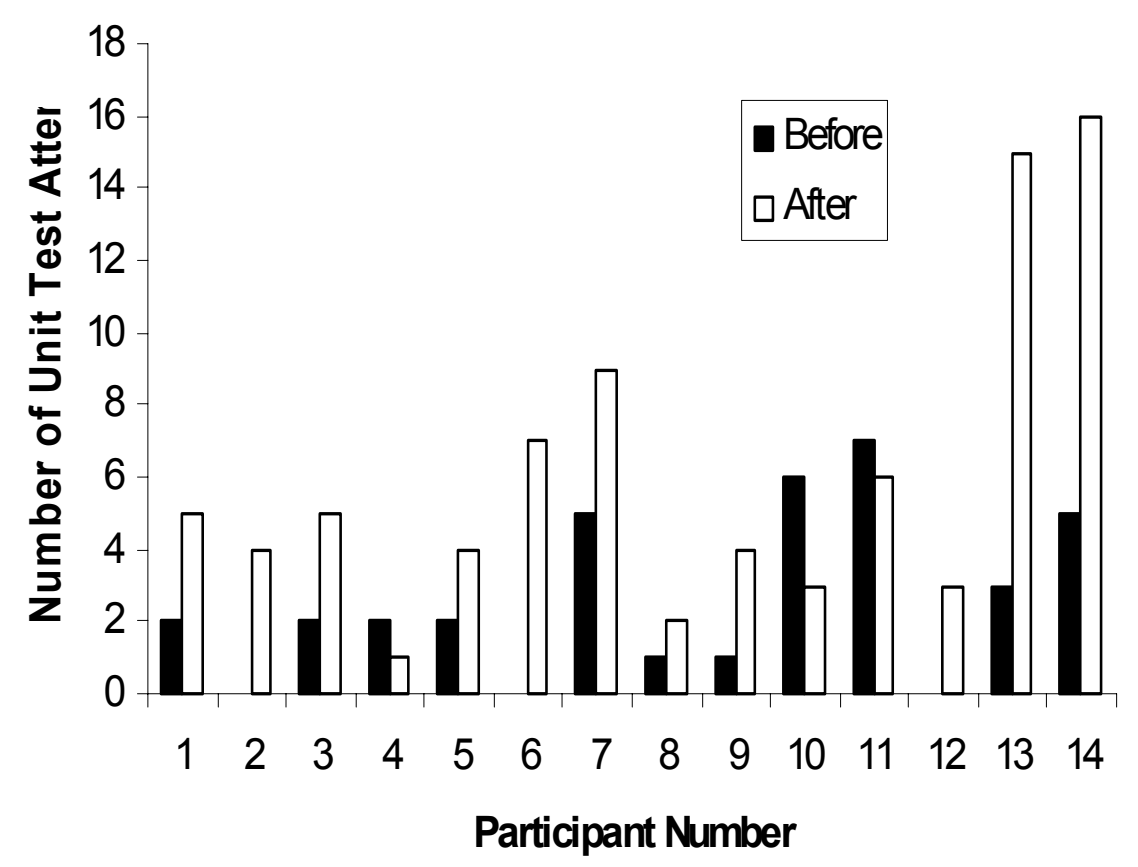

Figure 2. The total number of cancelled tests, by student, during the term before and after the conditional pass was introduced. 


\section{Qualitative Results}

Statements from students up to the announcement of the conditional pass result indicated that they were concerned about being able to write at a mastery level, or that the restudies were perceived as being very stressful. After the introduction of the conditional pass, students started to report liking the program better, and that they wished the conditional decision had been available all along. These observations confirmed the students' test-taking behavior in the course was increasing due to the change in feedback.

\section{Discussion}

The quantitative and qualitative results suggest that the use of a conditional decision may be an effective tool for helping students provide mastery-level answers in higher education courses. The addition of the conditional pass coincided with a dramatic increase in the self-paced test-taking activity, reduced number of cancelled tests, and positive self reports on the part of the students. Therefore, it appears that the basis for this study is confirmed: the restudy was serving as a punitive consequence for below-mastery textual responses.

While it may seem unconventional to use a conditional pass in a mastery-based system, previous iterations of CAPSI used such a procedure. What is clear from the data is this: The increase in student test-taking is an indication of increased persistence (response rate) and student engagement (increased response rate and less avoidance), which is linked to increased performance in PSI courses. By possibly providing students a less punitive environment in which to write and revise, while still maintaining mastery criteria, CAPSI was utilized in a way that for many students has the potential to increase persistence in developing their writing and thinking skills.

The use of feedback provides information that the answer is "close" is similar to the process involved in "shaping" (Martin \& Pear, 2003), in which successive approximations to a target behavior are reinforced. In the case of the conditional, we might think of the consequence involving some praise as a reinforcer for being closer to mastery, and that the subsequent revision in the writing is one more approximation to a mastery-level set of responses. Using these behavioral procedures, we can adapt them to environments such as CAPSI or other media to help improve student performance via feedback from more-able peers and instructors regarding what is required to provide mastery-level answers.

It should be pointed out that not all students are initially successful in this system. A few students still had some difficulty achieving mastery. The reasons for this are not entirely clear, but some observations should be noted here. First, some students tend to procrastinate in starting to write their unit tests. Second, some students appeared to have difficulty learning from or incorporating feedback into subsequent answers. For example, it was observed that feedback provided on a particular answer involving a restudy result was ignored on subsequent unit test, where the same question appeared. In fact, the student's answer on this test was exactly the same as on the previous test. This indicates that perhaps the student did not agree with the feedback, did not know how to incorporate the feedback, or simply did not read it. If it was the case that they did not agree with the feedback, then an option was to appeal the result. By appealing the result, they may have obtained more information to help them in the course. If they did not know how to incorporate the feedback, or did not read the feedback, then more research on how to encourage students to ask for help needs to carried out.

Clearly, using CAPSI and other PSI-like programs that utilize the power of the internet provides an exciting and fertile ground in which to conduct future educational research. With its stress on the written word, CAPSI and other PSI-based methods can be of great assistance in campus-wide projects 
whose aim is to increase the amount and quality of student writing. As Skinner (1959) pointed out, writing is a form of textual (verbal) behavior that is shaped through a process involving the writer and reviewers. As behavior analysts increasingly work with colleagues, administrators, and students who are not familiar with the behavioral paradigm, it is important to learn to conceptualize (speak) in a way that make communication with others possible. As such, the three paradigms (cognitive, constructivist, and behavioral) synthesize into combined efforts to increase the pedagogical effectiveness of these tools, the future looks bright for using the underlying behavioral processes effectively to increase student motivation to attempt and learn how to write at the higher level of education.

\section{References}

Bridges, B. K., \& Kuh, G. D. (2004). The National Survey of Student Engagement: A new indicator for postsecondary accountability. In R. Kazis, J. Vargas, \& N. Hoffman (Eds.)

Double the numbers: Increasing postsecondary credentials for underrepresented youth. Cambridge, MA: Harvard Education Press.

Buskist, W., Cush, D., \& DeGrandpre, R. J. (1991). The life and times of PSI. Journal of Behavioral Education, 1, 215 - 234.

Crone-Todd, D. E., \& Pear, J. J. (2001). Application of Bloom's Taxonomy to PSI. Behavior Analyst Today, 3, $204-210$.

Crone-Todd, D. E., Pear, J. J., \& Read, C. N. (2000). Operational definitions for higher order thinking objectives at the post-secondary level. Academic Exchange Quarterly, 4(3), 99-106.

Facione, P.A. (1997). Critical thinking: What it is and why it counts. Located on the California Academic Press Web site at URL: http://www.calpress.com/critical.html.

Grant, L. K., \& Spencer, R. E. (2003). The personalized system of instruction: review and applications to distance education. Retrieved September 25, 2005 from the International Review of Research in Open and Distance Learning website: http://www.irrodl.org/content/v4.2/grant-spencer.html

Goodwin, C. J. (2005). Research in psychology: methods and design (4rd ed.). Hoboken, NJ: John Wiley $\&$ Sons.

Halpern, D. F. (1998). Teaching critical thinking for transfer across domains. American Psychologist, 53, 449-455.

Johnson, K. R., \& Ruskin, R. S. (1977). Behavioral instruction: An evaluative review. Washington, DC: American Psychological Association.

Keller, F. S. (1968). "Good-bye teacher ..." Journal of Applied Behavior Analysis, 1, 79-89.

Kulik, J., Kulik, C. L. C., \& Cohen, P. A. (1979). A meta-analysis of outcome studies of Keller's Personalized System of Instruction. American Psychologist, 34, 307 - 318.

Martin, G., \& Pear, J. (2003) Behavior modification: What it is and how to do it (7h ed.). Upper Saddle River, NJ: Prentice Hall.

Martin, T. L., Pear, J. J., \& Martin, G. L. (2002a). Feedback and its effectiveness in a computer-aided personalized system of instruction course. Journal of Applied Behavior Analysis, 35, 427-430. 
Martin, T. L., Pear, J. J., \& Martin, G. L. (2002b). Analysis of proctor marking accuracy in a computeraided personalized system of instruction course. Journal of Applied Behavior Analysis, 35, 309312.

National Survey of Student Engagement. (2000). NSSE 2000 Overview, Indiana University Center for Postsecondary Research and Planning, Bloomington, IN.

Pear, J. J., \& Crone-Todd, D. E. (1999). Personalized system of instruction in cyberspace. Journal of Applied Behavior Analysis, 32, 205-209.

Pear, J. J., \& Crone-Todd, D. E. (2002). A social constructivist approach to computer-mediated instruction. Computers \& Education, 38, 221-231.

Pear, J. J., Crone-Todd, D. E., Wirth, K. M., \& Simister, H. D. (2001) Assessment of thinking levels in students' answers. Academic Exchange Quarterly, 5(4), 94-98.

Pear, J. J., \& Kinsner, W. (1988). Computer-aided personalized system of instruction: An effective and economical method for short- and long- distance education. Machine-Mediated Learning, 2, $213-$ 237.

Peterson, N. (1982). Feedback is not a new principle of behavior. Behavior Analyst, 5, 101-102.

Skinner, B. F. 1957. Verbal behavior. New York: Appleton-Century-Crofts.

Tierney, R. J., \& Shanahan, T. (1991). Research on the reading-writing relationship: interactions, transactions, and outcomes. In R. Barr, M. L. Camil, P. Mosenthal, \& P. D. Pearson (Eds.), Handbook of Reading Research (vol. 2, pp. 246-280). New York: Longman.

\title{
Author contact information:
}

Darlene E. Crone-Todd, Ph.D.

Div. of Counselor Education \& Psychology,

DSU Box 3142,

Delta State University,

Cleveland, MS 38732.

Email: dctodd@deltastate.edu

\author{
Heidi L. Eyre \\ Department of Psychology \\ Jacksonville State University \\ 700 Pelham Road, \\ Jacksonville, AL, 36265-1602 \\ Email: heyre@jsu.edu \\ Scott A. Hutchens \\ Division of Counselor Education and Psychology \\ Delta State University \\ Ewing Hall 335 \\ DSU Box 3142 \\ Cleveland, MS 38733
}


Email: shutchen@deltastate.edu

J. Reid Jones

Division of Counselor Education and Psychology

Delta State University

Ewing Hall 335

DSU Box 3142

Cleveland, MS 38733

Email: rjones@deltastate.edu

Joseph J. Pear

Department of Psychology

University of Manitoba

190 Dysart Rd

Winnipeg, MB R3T 2N2

Canada

Email: pear@cc.umanitoba.ca

\section{Advertising in the Behavior Analyst Today}

Advertising is available in The Behavior Analyst Today. All advertising must be paid for in advance. Make your check payable to Joseph Cautilli. The ad copy should be in our hands at least 3 weeks prior to publication. Copy should be in MS Word or Word Perfect, RTF format and advertiser should include graphics or logos with ad copy.

The prices for advertising in one issue are as follows:

$$
\text { 1/4 Page: \$50.00 1/2 Page: } \$ 100.00 \text { Full Page: } \$ 200.00
$$

If you wish to run the same ad in both issues for the year, you are eligible for the following discount:

1/4 Pg.: \$40 - per issue 1/2 Pg.: \$75 - per issue Full Page: $\$ 150.00$ - per issue

An additional one-time layout/composition fee of $\mathbf{\$ 2 5 . 0 0}$ is applicable

For more information, or place an ad, contact Halina Dziewolska by phone at (215) 462-6737 or e-mail at: halinadz@hotmail.com 